\title{
Facilitating Dental Student Reflections: Using Mentor Groups to Discuss Clinical Experiences and Personal Development
}

\author{
Sebastiaan Koole, MSc, PhD; Veronique Christiaens, DDS, MSc; \\ Jan Cosyn, DDS, MSc, PhD; Hugo De Bruyn, DDS, MSc, PhD
}

Abstract: Despite the consensus on the importance of reflection for dental professionals, a lack of understanding remains about how students and clinicians should develop their ability to reflect. The aim of this study was to investigate dental students' and mentors' perceptions of mentor groups as an instructional method to facilitate students' reflection in terms of the strategy's learning potential, role of the mentor, group dynamics, and feasibility. At Ghent University in Belgium, third- and fourth-year dental students were encouraged to reflect on their clinical experiences and personal development in three reflective mentor sessions. No preparation or reports afterwards were required; students needed only to participate in the sessions. Sessions were guided by trained mentors to establish a safe environment, frame clinical discussions, and stimulate reflection. Students' and mentors' perceptions of the experience were assessed with a 17-statement questionnaire with response options on a five-point Likert scale ( $1=$ totally disagree to $5=$ totally agree). A total of 50 students and eight mentors completed the questionnaire (response rates $81 \%$ and $89 \%$, respectively). Both students and mentors had neutral to positive perceptions concerning the learning potential, role of the mentor, group dynamics, and feasibility. The mean ideal total time for sessions in a year was 99 minutes (third-year students), 111 minutes (fourth-year students), and 147 minutes (mentors). Reported reflective topics related to patient management, frustrations, and practice of dentistry. Overall mean appreciation for the experience ranged from 14.50 to 15.14 on the 20-point scale. These findings about students' and mentors' positive perceptions of the experience suggest that mentor groups may be a potentially valuable strategy to promote dental students' reflection.

Dr. Koole is Educational and Research Coordinator, Department of Periodontology and Oral Implantology, Ghent University, Belgium; Dr. Christiaens is a PhD student, Department of Periodontology and Oral Implantology, Ghent University, Belgium; Dr. Cosyn is Associate Professor, Department of Periodontology and Oral Implantology, Ghent University, Belgium and Visiting Professor, Department of Periodontology and Oral Implantology, Free University of Brussels, Belgium; and Dr. De Bruyn is Professor, Department of Periodontology and Oral Implantology, Ghent University, Belgium and Visiting Professor, Department of Prosthodontics, Malmö University, Sweden. Direct correspondence to Dr. Sebastiaan Koole, Ghent University Dental School, De Pintelaan 185, 1P8, 9000 Ghent, Belgium; +3293324017; sebastiaan.koole@ugent.be.

Keywords: dental education, mentors, learning, reflection, clinical experience, individual development, critical thinking

Submitted for publication 1/5/16; accepted 4/19/16

$\mathrm{D}$ ental professionals work in challenging environments. Knowledge about oral pathology and treatment planning is increasing exponentially, patients are more demanding than ever, and multidisciplinary collaboration has become the standard of care. Consequently, dental education should not be limited to the mastery of knowledge and clinical skills, but must also help students become reflective practitioners. ${ }^{1-5}$ Dentists should engage themselves in a continuous process of reviewing clinical actions and results, identifying learning goals, and planning future strategies in order to deliver the highest quality care. ${ }^{6,7}$

Despite the consensus on reflection as an important attribute for dental professionals, there is a lack of guidelines about strategies to aid students and clinicians in developing their ability to reflect. ${ }^{6,8}$ As an approach to reflection, Bourner suggested differentiating between the process and content of reflection. ${ }^{9}$ The first can be described as a metacognitive process involving three elements: awareness, analysis, and outcome. ${ }^{6,10}$ Reflections can be assessed based on these process elements. For example, the student should demonstrate a broad awareness of the situation, including his or her own thoughts and feelings and those of others; the student then poses critical questions and focuses on future actions/plans.

However, the content of reflection has a subjective nature and is difficult to evaluate. Reflections can be highly relevant to some but irrelevant to 
others. Nevertheless, based on the theory of action developed by Argyris and Schön, reflections have been characterized by Greenwood and by Rushmer et al. as single-, double-, and triple-loop learning. ${ }^{11,12}$ Reflections identified as single-loop learning focus on instrumental problem-solving: problems are identified, and a solution is sought ("How can I fix this?"). Double-loop learning is the result of reflections focused on understanding the mechanisms at the basis of a problem, including assumptions, norms, values, and social relationships grounding human actions ("How does this work?"). Triple-loop learning considers the context in which the understandings are developed and the use of frameworks that have been used ("Why do I think this is a problem?").

To operationalize reflection in education, students are most frequently asked to write their reflections in a report that is analyzed for process or content. ${ }^{13,14}$ Other approaches are based on portfolios ${ }^{15}$ or interactions between a supervisor and students. ${ }^{16}$ The latter has the advantage that, by asking the correct questions, a supervisor can guide a student through the process of reflection.

Whereas in the past reflecting on one's own actions was considered an individual process only, currently reflection is also considered to be a group activity. Discussing reflections with multiple peers is enriching as more participants can increase the area of awareness, introduce additional perspectives, and create a stimulating and critical environment based on questions and reactions. Furthermore, previous studies have demonstrated that discussion groups are positively perceived by dental students. ${ }^{17,18}$ Nevertheless, studies by Koole et al. about discussion groups in terms of clinical reasoning ${ }^{19}$ and by Bush and Bissell ${ }^{18}$ and Koole et al. ${ }^{16}$ about reflective discussion groups emphasized the importance of supervision. First, supervisors are moderators, preventing the discussion from devolving into fruitless social talk. Second, in reflective discussions, supervisors may influence the content of reflections. In Koole et al., two reflective group discussions were led by two supervisors using the same semistructured format but with different contents based on single-loop versus double-loop learning. ${ }^{16}$ That study suggested that the questioning by the supervisors may have influenced the content of reflections in the discussion groups. In addition, Schaub-de Jong et al. identified the support of self-insight, creation of a safe environment, and encouragement of self-regulation as essential teacher competencies to facilitate reflective learning in small groups. ${ }^{20}$
The findings from these studies suggest that reflective mentor groups focused on discussion of clinical experiences and individual development as a dentist may be a promising strategy to stimulate reflections in dental students. The aim of this study was therefore to investigate both dental students' and mentors' perceptions of mentor groups as an instructional method to facilitate students' reflection in terms of the strategy's learning potential, role of the mentor, group dynamics, and feasibility.

\section{Methods}

This study was approved by the Ghent University Hospital Ethics Committee. At Ghent University in Belgium, to earn the degree of Master in Dentistry, students follow a five-year program consisting of three years of bachelor's level training and two years of master's level training. The first years are designed to develop a solid background of theoretical knowledge and the acquisition of basic dental skills. As the program progresses, students are gradually exposed to clinical activities as the fulcrum shifts towards clinical education. After introductory observational/ assisting sessions in year two, students perform supervised clinical activities themselves, starting from year three and increasing in time towards the end of the program.

Reflection is taught throughout the program. In year one, students are introduced to the concept of reflection, including the process of reflection in terms of the awareness of experiences, analysis, and outcome. ${ }^{6}$ From year two onwards, students are asked to reflect on their experiences during the observational/ assisting sessions they attend. For each experience, they are required to compose a brief report including a clinical focus (description of activity, patient problem, history, examination, diagnosis, treatment, communication, and feedback of supervisor) and a reflective focus (description of learning goals, notable positive/negative experiences, what was learned, and definition of future learning goals). Each item has a maximum text amount of two lines to stimulate thinking over writing.

In addition, reflective mentor groups were introduced in year three of the program in academic year 2013-14. The purpose of this initiative was to stimulate students to reflect on their clinical experiences and their individual development as a dentist. Students were placed into mentor groups of seven or eight students. During the year, each group had 
three meetings. Students were not evaluated during the meetings but were required to attend all three sessions. A preparation or report afterwards was not required, as the focus was on the reflective discussion. Each meeting had a themed scenario. The first meeting was about getting to know each other and establishing a safe environment. The second meeting focused on critical incidents, and the third meeting was about the ideal dentist. Besides these themes, students were allowed to introduce their own discussion topics. The role of the mentor was to create a safe environment in which students felt free to express themselves, to frame discussions of student experiences, and to initiate and stimulate a reflective discussion.

To take on the role of mentors who would serve as facilitators of reflection, clinically experienced staff members received a two-hour introduction to the concept of reflection and how to stimulate reflection in students. Furthermore, they had two additional mentor sessions a year in which their experiences as a mentor were discussed in terms of learning from each other. Actual discussions in the groups were not discussed because of the central rule: discussions stay within the group. This rule applied to both students and mentors and was crucial to establish a safe learning environment. The mentor groups continued in the same composition throughout years three and four.

To investigate the impact of this initiative on stimulating reflection among the students and mentors, we developed a questionnaire consisting of 17 statements on learning potential $(n=3)$, role of the mentor $(n=4)$, group dynamics $(n=4)$, and feasibility $(n=6)$. Respondents scored the statements on a five-point Likert scale from $1=$ totally disagree to $3=$ neutral to $5=$ totally agree. The mentors' version of the questionnaire had an extra statement about their training. In addition, the questionnaire asked about the ideal frequency and length of sessions, particularly interesting reflections, and level of general appreciation of this initiative on a 20-point scale.

During the last session of academic year 201415 , all students and mentors were asked to complete the questionnaire. In total, 28 students and four mentors in year three and 34 students and five mentors in year four received a questionnaire. Questionnaires were anonymous. Completed questionnaires were collected by the mentors in a closed envelope and returned to the principal investigator (SK).

SPSS for Windows, Version 22.0 (IBM Corp., Armonk, NY, USA) was used to analyze responses to the statements, the ideal frequency and length of sessions, and respondents' general assessment of the experience. The reported reflections were analyzed thematically.

\section{Results}

A total of 50 students and eight mentors returned questionnaires, resulting in response rates of $81 \%$ and $89 \%$, respectively. The responses showed that the students were neutral to positive about the statements related to learning potential (average scores between 3.07 and 3.85 on the five-point scale). The mentors were slightly more positive, with average scores between 3.63 and 4.38. In general, the students and mentors agreed on the importance of the mentor's role during reflective group sessions. The students scored between 3.30 and 4.20 and the mentors between 3.38 and 4.75 on the mentor questions.

All statements about group aspects were perceived as beneficial for reflections except for the item about mentor groups' facilitating improved understanding of clinical experiences, which was rated negative to neutral (average score of 2.87) by students in the fourth year. The strategy used in the three sessions (with no preparation or reports afterwards and under guidance of a mentor to facilitate reflections) was perceived as positive with average student scores between 3.17 and 4.14 and average mentor scores between 3.50 and 5.00. The mentors were neutral about the training they received in preparation for their role as a mentor (average score 3.13). Table 1 provides a detailed overview of all reactions to the statements by the third-year students, fourth-year students, and mentors. Regarding the ideal frequency and length of sessions, third- and fourth-year students proposed a mean total time of 99 and 111 minutes a year, respectively. Mentors suggested a mean total time of 147 minutes a year.

A total of 24 students and mentors reported interesting reflective topics that had been discussed in their groups. Three themes were identified: patient management, frustrations, and practice of dentistry. The reflective topics in each theme are summarized in Table 2. The general appreciation of the third- and fourth-year students was on average 14.50 and 14.70 on a scale of 20, with a range of 12-18 and 9-20, respectively. The mentors evaluated this initiative on average 15.14 out of 20 (range 12-18). 
Table 1. Responses to survey statements by third-year students (Y3), fourth-year students (Y4), and mentors (M)

Statement

$\begin{array}{lllllll}1 & 2 & 3 & 4 & 5 & \mathrm{M} & \mathrm{SD}\end{array}$

Learning potential

Reflection is an important attribute for dental students/dentists.

Reflective group sessions are instructive.

I am positive about participating in reflective group sessions/being a mentor.

$\begin{array}{cccccccc}Y 3 & 0 & 0 & 5 & 13 & 2 & 3.85 & 0.60 \\ Y 4 & 1 & 3 & 7 & 13 & 6 & 3.67 & 1.03 \\ M & 0 & 0 & 2 & 3 & 3 & 4.13 & 0.83 \\ Y 3 & 0 & 0 & 10 & 9 & 1 & 3.55 & 0.60 \\ Y 4 & 0 & 4 & 18 & 6 & 2 & 3.20 & 0.76 \\ M & 0 & 1 & 3 & 2 & 2 & 3.63 & 1.06 \\ Y 3 & 0 & 4 & 9 & 3 & 4 & 3.35 & 1.04 \\ Y 4 & 1 & 5 & 16 & 7 & 1 & 3.07 & 0.83 \\ M & 0 & 2 & 4 & 1 & 1 & 3.13 & 0.99\end{array}$

\section{Role of mentor}

The themes introduced by the mentor were beneficial for the discussions.

The presence of a mentor is beneficial for the reflective group sessions.

The mentor facilitates reflection by posing stimulating questions.

The mentor frames the discussion about (clinical) experiences with personal experiences.

$\begin{array}{cccccccc}\mathrm{Y} 3 & 1 & 4 & 5 & 8 & 2 & 3.30 & 1.08 \\ \mathrm{Y} 4 & 0 & 5 & 11 & 13 & 1 & 3.32 & 0.79 \\ \mathrm{M} & 0 & 1 & 3 & 4 & 0 & 3.38 & 0.74 \\ \mathrm{Y} 3 & 0 & 1 & 1 & 11 & 7 & 4.20 & 0.77 \\ \mathrm{Y} 4 & 0 & 0 & 6 & 18 & 6 & 4.00 & 0.64 \\ \mathrm{M} & 0 & 0 & 3 & 4 & 1 & 3.75 & 0.71 \\ \mathrm{Y} 3 & 0 & 0 & 4 & 13 & 3 & 3.95 & 0.60 \\ \mathrm{Y} 4 & 0 & 0 & 2 & 21 & 7 & 4.17 & 0.53 \\ \mathrm{M} & 0 & 0 & 4 & 2 & 2 & 3.75 & 0.89 \\ \mathrm{Y} 3 & 0 & 2 & 2 & 10 & 6 & 4.00 & 0.92 \\ \mathrm{Y} 4 & 0 & 0 & 5 & 16 & 9 & 4.13 & 0.68 \\ \mathrm{M} & 0 & 0 & 0 & 2 & 6 & 4.75 & 0.46\end{array}$

\section{Group dynamics}

Group reflections are beneficial compared to individual reflections.

Reflective group sessions help students to acquire an improved understanding of their development as a dentist.

Reflective group sessions help students to acquire an improved understanding of their clinical experiences.

Reflective group sessions prepare students to discuss patient cases with colleagues in the future.

\section{Feasibility}

Three sessions a year is the ideal frequency for students to reflect about clinical experiences.

The strategy used (without the need to present a written preparation and report afterwards) is good.

The strategy that students plan sessions in coordination with their mentor is feasible.

I/students felt comfortable to share my/their personal thoughts freely during a reflective group session.

I/students experienced sufficient space to introduce personal thoughts during a reflective group session.

I/students experienced sufficient space to react to others' thoughts during a reflective group session.

$\begin{array}{cccccccc}\mathrm{Y} 3 & 0 & 0 & 4 & 12 & 4 & 4.00 & 0.65 \\ \mathrm{Y} 4 & 2 & 1 & 8 & 15 & 4 & 3.60 & 1.00 \\ \mathrm{M} & 0 & 0 & 1 & 3 & 4 & 4.38 & 0.74 \\ \mathrm{Y3} & 0 & 5 & 3 & 12 & 0 & 3.68 & 0.65 \\ \mathrm{Y} 4 & 1 & 6 & 14 & 6 & 3 & 3.13 & 0.97 \\ \mathrm{M} & 0 & 0 & 3 & 4 & 1 & 3.69 & 0.70 \\ \mathrm{Y} 3 & 0 & 0 & 9 & 8 & 3 & 3.70 & 0.73 \\ \mathrm{Y} 4 & 2 & 6 & 17 & 4 & 1 & 2.87 & 0.86 \\ \mathrm{M} & 0 & 0 & 6 & 1 & 1 & 3.38 & 0.74 \\ \mathrm{Y3} & 0 & 5 & 3 & 12 & 0 & 3.35 & 0.88 \\ \mathrm{Y} 4 & 0 & 4 & 13 & 10 & 3 & 3.38 & 0.85 \\ \mathrm{M} & 0 & 1 & 2 & 3 & 2 & 3.75 & 1.04\end{array}$

I was sufficiently prepared for my role as a mentor.

$\begin{array}{cccccccc}\text { Y3 } & 1 & 4 & 5 & 9 & 1 & 3.25 & 1.02 \\ \text { Y4 } & 0 & 6 & 10 & 11 & 3 & 3.37 & 0.93 \\ \text { M } & 1 & 0 & 1 & 2 & 4 & 3.50 & 1.20 \\ \text { Y3 } & 0 & 1 & 3 & 9 & 7 & 4.10 & 0.85 \\ \text { Y4 } & 0 & 0 & 7 & 11 & 11 & 4.14 & 0.79 \\ \text { M } & 0 & 0 & 0 & 3 & 5 & 4.63 & 0.52 \\ Y 3 & 1 & 2 & 3 & 9 & 5 & 3.75 & 1.12 \\ Y 4 & 2 & 4 & 13 & 9 & 2 & 3.17 & 0.99 \\ M & 0 & 0 & 1 & 5 & 2 & 4.13 & 0.64 \\ Y 3 & 0 & 1 & 4 & 10 & 5 & 3.95 & 0.83 \\ Y 4 & 0 & 0 & 4 & 18 & 8 & 4.13 & 0.63 \\ M & 0 & 0 & 0 & 1 & 7 & 4.88 & 0.35 \\ Y 3 & 0 & 0 & 5 & 11 & 4 & 3.95 & 0.69 \\ Y 4 & 0 & 0 & 3 & 20 & 7 & 4.13 & 0.57 \\ M & 0 & 0 & 1 & 1 & 6 & 4.63 & 0.74 \\ Y 3 & 0 & 0 & 5 & 9 & 6 & 4.05 & 0.76 \\ Y 4 & 0 & 0 & 4 & 19 & 7 & 4.10 & 0.61 \\ M & 0 & 0 & 0 & 0 & 8 & 5.00 & 0.00 \\ M & 0 & 0 & 2 & 1 & 5 & 4.38 & 0.92\end{array}$

Note: Variations in statements between student and mentor surveys are both displayed separated by a slash (/). Responses were based on a five-point scale ( $1=$ totally disagree to $3=$ neutral to $5=$ totally agree) and are also reported as mean (M) and standard deviation (SD). 


\section{Table 2. Identified themes and reflective topics reported by dental students and mentors}

\begin{tabular}{ll} 
Theme & \multicolumn{1}{c}{ Reflective Topic } \\
\hline Patient management & Communication with complex patients \\
& How to manage patients in general \\
& Managing medically/psychologically compromised patients \\
& How to say "no" to patients \\
& Delivering a diagnosis \\
Insurance? & Managing a dental practice in the future \\
Practice of dentistry & What kind of dentist do I want to become? \\
& What fears do dental students have? \\
& Accidents with injection needles \\
& Complaints about organization of the student clinic \\
Frustrations & Communication between students and supervisors \\
& Time pressure in the student clinic
\end{tabular}

\section{Discussion}

In reaction to the lack of published research about practical applications to operationalize reflection, this study sought to evaluate a strategy using mentor groups to facilitate reflections based on clinical experiences of dental students. Both the students and the mentors had neutral to positive perceptions about this initiative concerning learning potential, role of the mentor, group dynamics, and feasibility.

The main focus of the mentor groups was to facilitate meaningful discussions. Hence, students were not required to make any preparations before or reports afterwards about the reflective sessions. A previous study found an aversion in dental students toward written reflections, as opposed to reflecting per se. ${ }^{18}$ In our study, both students and mentors were positive about this approach of focusing on reflections without potentially reducing the students' motivation through the use of required writings.

Our results illustrated the importance of mentors in group discussions to facilitate reflections and to frame discussion of clinical experiences. Sandars described facilitation of reflection as non-judgmental questioning and acceptance of differences. ${ }^{21}$ Clinically experienced staff members were trained to facilitate reflections in our study. Although multiple training efforts were organized, the mentors were neutral when asked whether they felt sufficiently prepared. This finding demonstrates that clinical expertise is not enough and that training sessions for clinicians to become mentors should not be taken lightly. ${ }^{22}$ Additionally, to facilitate student reflec- tions, mentors should be trained in creating a safe environment in which students can reflect ${ }^{20,21,23}$ and converting social conversation and frustrations about educational programs into valuable reflective discussions. The latter were often reported as a theme on the questionnaire. Frustrations can elicit strong emotions and initiate reflections. ${ }^{23}$ However, they can also lead to students' unidirectionally venting their disgruntlement without considering their personal involvement. A mentor should manage this situation by converting the external attribute into an internal focus.

In contrast to the guidelines proposed by Aronson, ${ }^{23}$ the mentor groups in our study were not assessed. The idea of assessment is to provide students with feedback about their reflective skills. Scoring rubrics have been proposed, ${ }^{24,25}$ but they are mainly focused on the process of reflection, whereas mentor groups are all about the relevance of reflections. Furthermore, due to the group dynamics during the sessions, students received direct feedback from their peers and mentor.

Mentor groups were designed to present students with a low threshold of reflection. No additional reports were required, discussions were initiated by clinical experiences, mentors were trained to facilitate reflections, and students could directly interact with their peers. As a result, students were exclusively focused on their reflections and may have experienced their relevance. It is encouraging that the results showed that the students had a positive perception of the mentor groups, considering the fact that the reflective sessions were introduced as an addition to an already packed curriculum. 
Most of the students agreed with the question that asked if they felt comfortable sharing their personal thoughts during the sessions, indicating that the mentors succeeded in creating a safe environment. Nevertheless, the rule that the discussion stays within the group posed an important limitation to the study. Although the mentors were trained to facilitate reflective discussions, it remains unclear whether they actually achieved this goal. A related limitation is that students' actual improvement in reflection was not assessed, but only the participants' perceptions of the experience. Recording the sessions could provide the opportunity to analyze the discussions, but would violate the safe environment and hence influence the openness of participants. Another approach to ensure relevant reflective discussions is to increase the expertise of mentors to facilitate reflections in students. As they have a pivotal role during the session, they have an important impact on the outcome of discussions. Since each mentor had a different clinical background and predisposition to guide student groups, they should be continuously supported in their task. In our study, two additional sessions between mentors were organized. Nevertheless, these mentors were undecided about their preparedness for their role, suggesting that continuation of training sessions for mentors in the future is an important concern. A final limitation is that the study took place at one dental school, so its results may not be generalizable to students in other schools.

Future research should be directed towards the implementation of reflective learning and/or practice in dentistry. With the consensus about the importance of reflection, dental education and professional practitioners are in need of strategies to introduce the ability to reflect in daily practice. Hence, future research should be focused on the development of practical guidelines for both dental students and dentists on how to reflect, how to cultivate relevant reflections, how to integrate reflection in daily practice, and how to use group reflections as a strategy for improvement. Development and validation of new strategies to stimulate/facilitate reflection should involve both qualitative and quantitative research approaches and include collecting the perspectives of stakeholders, analyzing the reflections (process and content), and investigating the impact of reflections on learning/ clinical practice. Findings from such studies will facilitate the further advancement of understanding about the concept of reflection and will enable educators to evaluate the impact of the proposed strategies on learning. To fully understand the impact of reflection on dental education and clinical practice and to provide theory-based strategies to stimulate reflection, more studies are required.

\section{Conclusion}

This study described the use of mentor groups as a strategy to facilitate reflective discussions about clinical experiences and personal development among students. Mentor groups were appreciated by both the students and mentors and may be a potentially valuable approach in dental education to promote reflection and critical thinking. In support of implementing this strategy, we would make five recommendations. First, mentor groups should be integrated within a structure of reflective education. Students need to first learn about the concept of reflection and how to reflect (awareness, analysis, and outcome). Afterwards, mentor groups can be introduced to focus on the relevance of reflections. Second, discussions should be initiated by clinical experiences/situations and their significance for the students explored. Third, students should feel comfortable sharing their personal thoughts. The mentor has the important task of creating a safe environment. Trust is a big issue. A stable group composition throughout the sessions also supports the creation of a safe environment. Fourth, setting a low threshold aids the processing of learning to reflect by removing possible demotivating/ influencing factors (preparations, reflective reports, assessments), introducing a mentor to stimulate reflections, and encouraging interactions between students. Finally, mentors have a pivotal role during the sessions and are essential for success. Schools should invest the effort to train them well and provide continuous support between sessions.

\section{REFERENCES}

1. Cowpe J, Plasschaert A, Harzer W, et al. Profile and competences for the European dentist: update 2009. Eur J Dent Educ 2010;14:193-202.

2. Frenk J, Chen L, Bhutta ZA, et al. Health professionals for a new century: transforming education to strengthen health systems in an interdependent world. Lancet 2010; 376:1923-58.

3. Schön DA. The reflective practitioner: how professionals think in action. New York: Basic Books, 1983.

4. Schön DA. Educating the reflective practitioner. San Francisco: Jossey-Bass, 1987.

5. Hendricson WD, Andrieu SC, Chadwick DG, et al. Educational strategies associated with development of problem-solving, critical thinking, and self-directed learning. J Dent Educ 2006;70(9):925-36. 
6. Koole S, Dornan T, Aper L, et al. Factors confounding the assessment of reflection: a critical review. BMC Med Educ 2011;11:104.

7. Plack MM, Greenberg L. The reflective practitioner: reaching for excellence in practice. Pediatrics 2005;116: 1546-52.

8. Mann K, Gordon J, MacLeod A. Reflection and reflective practice in health professions education: a systematic review. Adv Health Sci Educ 2009;14:595-621.

9. Bourner T. Assessing reflective learning. Educ Train 2003;45:267-72.

10. Boud D, Keogh R, Walker D. Reflection: turning experience into learning. London: Kogan Page, 1985.

11. Greenwood J. The role of reflection in single and double loop learning. J Adv Nurs 1998;27:1048-53.

12. Rushmer R, Kelly D, Lough M, et al. Introducing the learning practice, II: becoming a learning practice. J Eval Clin Pract 2004; 10:387-98.

13. Wald HS, Reis SP. Beyond the margins: reflective writing and development of reflective capacity in medical education. J Gen Intern Med 2010;25:746-9.

14. Tsang AKL. Oral health students as reflective practitioners: changing patterns of student clinical reflections over a period of 12 months. J Dent Hyg 2012;86:120-9.

15. Koole S, Vanobbergen J, De Visschere L, et al. The influence of reflection on portfolio learning in undergraduate dental education. Eur J Dent Educ 2013;17:e93-9.

16. Koole S, Fine P, De Bruyn H. Using discussion groups as a strategy for postgraduate implant dentistry students to reflect. Eur J Dent Educ 2016;20:59-64.
17. Koole S, De Wever B, Aper L, et al. Using online periodontal case-based discussions to synchronize theoretical and clinical undergraduate dental education. Eur J Dent Educ 2012;16:52-8.

18. Bush H, Bissell V. The evaluation of an approach to reflective learning in the undergraduate dental curriculum. Eur J Dent Educ 2008;12:103-10.

19. Koole S, Vervaeke S, Cosyn J, De Bruyn H. Exploring the relation between online case-based discussions and learning outcomes in dental education. J Dent Educ 2014;78(11):1552-7.

20. Schaub-de Jong MA, Schönrock-Adema J, Dekker H, et al. Development of a student rating scale to evaluate teachers' competencies for facilitating reflective learning. Med Educ 2011;45:155-65.

21. Sandars J. The use of reflection in medical education: AMEE guide no. 44. Med Teach 2009;31:685-95.

22. Subramanian J, Anderson VR, Morgaine KC, Thomson WM. Effective and ineffective supervision in postgraduate dental education: a qualitative study. Eur J Dent Educ 2013; 17:e142-50.

23. Aronson L. Twelve tips for teaching reflection at all levels of medical education. Med Teach 2011;33:200-5.

24. Koole S, Dornan T, Aper L, et al. Using video cases to assess student reflection: development and validation of an instrument. BMC Med Educ 2012;12:22.

25. Wald HS, Borkan JM, Taylor JS, et al. Fostering and evaluating reflective capacity in medical education: developing the REFLECT rubric for assessing reflective writing. Acad Med 2012;87:41-50. 